\title{
Intimal Thickness of the Abdominal Aorta: A Postmortem Study
}

\author{
Saifun Naher', Humaira Nawsaba ${ }^{2}$, Shamim Ara $^{3}$, Md. Nowfel Islam ${ }^{4}$, AKM Khairuzzaman ${ }^{5}$, \\ Nahid Ahmed Khan ${ }^{6}$
}

\begin{abstract}
:
A study was done to find out the intimal thickness of abdominal aorta of Bangladeshi males of different ages. The subjects were divided into lower ( $8-29$ years), middle (30-40 years), higher (42-92 years) age groups. Six good Mallory-Azan stained histological slides, section from lower most $2 \mathrm{~cm}$ portion of the abdominal aorta along the margin of its bifurcation of three age groups were prepared for this study. After standardizing the ocular micrometer with the stage micrometer for the particular objective and eyepiece, each study slide was placed in the place of stage micrometer and intimal thickness was measured in ocular micrometer division. Unpaired student ' $t$ ' test for statistical analysis revealed that the mean intimal thickness varied significantly $(P<0.05)$ in the middle and the higher age groups in comparison to that in the lower age group.
\end{abstract}

\section{Introduction:}

Atherosclerosis is the most common and important pattern of arterial disease, and it causes thickening and hardening of the arterial wall. The lesion is developed following endothelial injury ${ }^{2}$. Atherosclerosis refers to a group of disorders that have a common thickening and loss of elasticity of the arterial walls. The changes of atherosclerosis initially

1. Associate Professor and Head, Department of Anatomy, Holy Family Red Crescent Medical College, Dhaka.

2. Professor and Head. Department of Anatomy, Sir Salimullah Medical College. Dhaka.

3. Professor and Head, Department of Anatomy, Dhaka Medical College. Dhaka.

4. Associate Professor, Department of Pathology, National Institute of Ophthalmology, Dhaka.

5. Assistant Professor and Head, Department of Biochemistry, Northem Intemational Medical College. Dhaka.

6. Lecturer. Department of Anatomy, Holy Family Red Crescent Medical College, Dhaka. involve the intimal layer of the arterial wall in which there is focal accumulation of a variety of complex lipids, proteins and carbohydrates; cellular components, such as smooth muscle cells and macrophage like cells, blood and blood constituents; and in more advanced lesion, high concentrations of mineral, particularly calcium².

A variety of lesions may occur in and from the lesions including ulcerations, thrombosis, embolism, calcification and aneurysm ${ }^{3}$. The clinical manifestations of atherosclerosis depend on the site of the lesion and the vulnerability of the organ supplied ${ }^{4,5}$. The advanced lesion of atherosclerosis reduces the blood flow in arteries and ultimately leads to occlusion of the individual arteries ${ }^{6}$. Atherosclerosis usually affects the male persons more than the female $\mathrm{e}^{7.1}$. 
Hence, the present study was done to find out the intimal changes directed towards measuring intimal thickness of abdominal aorta of Bangladeshi males of different ages.

\section{Materials and method:}

The lower most $2 \mathrm{~cm}$ of the abdominal aorta was taken for microscopic study. The specimens were collected from the subjects divided into lower (8-29 years), middle (30-40 years) and higher (42-92 years) age groups.

\section{Preparation of slides:}

The arteries were kept in Carnoy's fixative for at least six hours. After fixation, each segment of artery was washed in tap water and were processed for dehydration, infiltration and embedding in liquid paraffin separately. Six micron thick cross sections were prepared from the blocks. For right renal arteries sections were made from $18(6 \times 3)$ blocks from eighteen different individuals selected through random samping. The sections were mounted on slides, stained, and cover slipped. From each block three sections were taken. Section from all these blocks were stained with Mallory-Azan stain.

One good slide from six different abdominal aorta of each age group were taken for microscopic measurement. Thus, a total number of 18 Mallory-Azan stained slides were used for microscopic study.

\section{Measurement of intimal thickness:}

The slides were examined under light microscope for measuring intimal thickness using $\times 10$ objectives and $X 10$ eye piece.

A piece of transparent plastic sheet (about cover slip size) was divided into four equal quadrants by drawing two straight lines at right angles to each other by a fine sharp needle( Fig.-1). Then it was placed on the studying section in such a way that meeting point of the two straight lines was placed at the centre of the lumen of the artery so that the artery was divided into four more or less equal quadrants. Then under a light microscope, the greatest thickness of the intima were measured for each quadrant. The mean of these four values were taken as an estimate of intimal thickness of the right renal arterial sections.

For measuring the intimal thickness, an ocular micrometer was put into the eye piece of a light microscope. A metalic 'slide' standardized in length, breadth and thickness with conventional glass slide was put on the stage for standardization of the ocular micrometer. The metalic 'slide' that had an inbuilt micrometer (the stage micrometer) at its central glass made part was used for measuring intimal thickness. The slides were examined under light microscope for measuring intimal thickness using $\times 10$ objectives and $\times 10$ eyepiece as mentioned above. The magnifying power of the eye piece was kept constant (x10).

After standardizing the ocular micrometer with the stage micrometer for the particular objective and eye piece, each study slide was placed in place of stage micrometer and the intimal thickness was measured in terms of ocular micrometer division. The number of ocular micrometer divisions was then converted into absolute values in micrometer $(\mu \mathrm{m})$ following standardization procedure described below.

For, standardization, the stage micrometer calibration was focused under the objective to be used and the ocular micrometer calibrations was superimposed on them in such way that 
starting mark on the ocular micrometer matches exactly with a starting mark on the stage micrometer. Then the marker on the stage and ocular micrometer that correspond to each other most closely was noted. In this way, determination of how many of the smallest division of the ocular micrometer corresponded to how many smallest division of the stage micrometer was done.

\section{Results:}

The intimal thicknesses of the abdominal aorta in the different age groups are presented in Table-I.
From the table it is revealed that a trend of increasing mean intimal thickness of the abdominal aorta in each age group along with the advancement of ages. It is also evident from the table that a significant difference $(\mathrm{p}<0.05, \mathrm{p}<0.05)$ was found in mean intimal thickness of abdominal aorta, between the lower and middle age groups as well as the lower and higher age groups. No significant differences were found between middle age group and higher age group of the abdominal aorta.

With this, the following calculations were done:

100 smallest division of stage micrometer $=1 \mathrm{~mm}=1000 \mu \mathrm{m}$

1 smallest division of stage micrometer $=1000 \div 100=10 \mu \mathrm{m}$

In low magnification (X 10 objective, $\mathrm{X} 10$ eye piece):

97 smallest division of ocular micrometer matches with 100 smallest divisions of stage micrometer.

So, one smallest division of ocular micrometer matches will $100 \div 97$ or 1.03 smallest divisions of stage micrometer.

Because one stage micrometer division $=10 \mu \mathrm{m}$, therefore, one ocular micrometer division $=1.03 \times 10 \mu \mathrm{m}=10.3 \mu \mathrm{m}$.

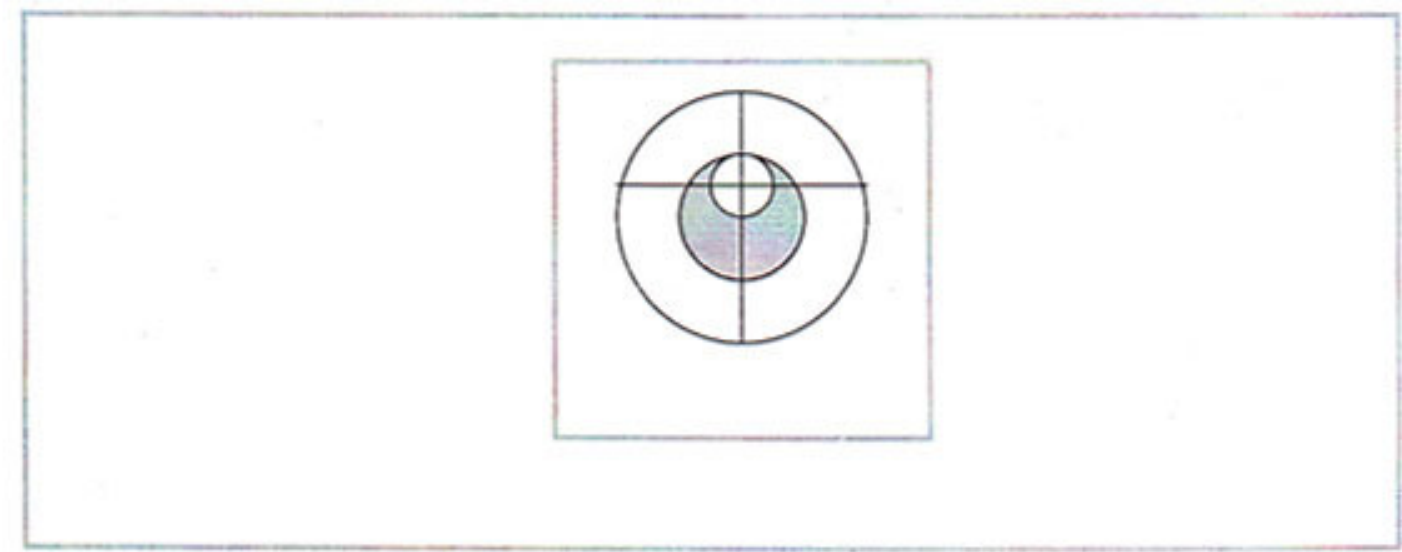

Figure: 1 Diagrammatic representation of the division of plastic sheet into four equal quadrants and its placement on the blood vessel for measuring its intimal thickness from the apical surface of the endothelium to the internal elastic lamina. 
Table-I: Comparison of intimal thickness of the abdominal aorta in three age groups

\begin{tabular}{|c|c|c|c|}
\hline \multirow{2}{*}{$\begin{array}{c}\text { Age group } \\
\text { (years) }\end{array}$} & $\begin{array}{c}\text { Number of } \\
\text { abdominal aorta }\end{array}$ & \multicolumn{2}{|c|}{ Intimal thickness ( in micrometer) } \\
\cline { 3 - 4 } & Rower \\
$(8-29)$ & 06 & $105.58-236.90$ & Mean \pm SD \\
\hline $\begin{array}{l}\text { Middle } \\
(30-40)\end{array}$ & 06 & $208.58-551.05$ & $318.87 \pm 124.10$ \\
\hline $\begin{array}{l}\text { Higher } \\
(42-92)\end{array}$ & 06 & $208.58-687.53$ & $379.38 \pm 178.79$ \\
\hline & $\begin{array}{l}\text { Lower age vs Middle age }<0.05^{*} \\
\text { Lower age vs Higher age }<0.05^{*} \\
\text { Middle age vs Higher age }>0.10^{\text {ns }}\end{array}$ \\
\hline
\end{tabular}

Statistical analysis done by unpaired student's ' $t$ ' test, $n s=$ not significant, ** = significant.

\section{Discussion:}

The present study showed that the mean intimal thickness increased from the lower $(8$ 29 years) through the middle ( $30-40$ years) to the higher (42-92 years) age groups. That is, thickness increased along with the advancement of ages and the difference was statistically significant between the lower and middle age group as well as lower and higher age group. This finding was quite in conformity with the findings of the previous researchers working with thoracic aorta, coronary arteries and also abdominal aorta ${ }^{1.2 .8}$. Abdominal aorta ends by dividing into two common iliac arteries. It has been postulated that specific arterial sites, such as branches, bifurcation and curvatures caused characteristics alteration in the flow of blood. At these sites laminar flow of blood is changed into turbulent flow. The explanation might be given on the basis of anatomical and haemodynamic factors. It is known that at the site of branching there is alteration in the direction of blood flow and blood flow becomes turbulent instead of laminar flow.
The type of blood flow is a determinant factor in the genesis of atherosclerosis. Many studies have been done to find out the pathogenesis of this disorder where the cause of increased thickness had been pointed out. It became evident from the previous research works that atherosclerosis is a disease that stimulates proliferative changes in the different cellular components of the arterial wall as well as stimulates the secretion of certain chemotactic substances that attract the blood elements to invade the intima and to proliferate. All these biochemical changes ultimately lead to the increase in the intimal thickness ${ }^{2.9}$. As it is a progressive disorder this process of thickening is most likely to continue at an increasing rate as age advances.

\section{References:}

1. Schoen FJ, Cotran RS. Blood vessels. In: Cotran RS, Kumar V, Collins T (editors). Robin's Pathologic Basis of Disease, Seventh Edition. Philadelphia: WB Swanders Company, 2004. pp-516-25. 
2. Begum S. Postmortem study of atherosclerosis in the abdominal aorta of Bangladeshi males [thesis]. Dhaka: Bangabandhu Sheikh Mujib Medical University, 1998.

3. Holman RL, McGill HC Jr., Strong JP, Geer JC. The natural history of atherosclerosis: the aortic lesions as seen in New Orleans in middle of the 20th century. Am J Pathol 1958; 34: 209-30.

4. Bloomfield P, Bradbury A, Grubb NR. Newby DE. Cardiovascular disease. In: Boon NA, Colledge NR, Walker BR, Hunter JAA (editors). Davidson's Principles and Practice of Medicine, Twentieth edition. London: ELBS with Churchill Livingstone, 2006. pp- 578-80.
5. Bierman EL. Disorders of vascular system. In: Isselbacher $\mathrm{KJ}$, Braunwald $\mathrm{E}$, Wilson JD, Martin JB, Fauci AS, Kasper DL (editors). Harrison's Principle of Internal Medicine, Thirteenth edition. New York: McGraw-Hill, 1994. pp-1106-16.

6. Ross R. Atherosclerosis-An inflammatory disease. N Eng J Med 1999; 340: 115-26.

7. Strong JP, Solberg LA, Restrepo C. Atherosclerosis in persons with coronary heart disease. Lab Invest 1968 ; 18:527-37.

8. Islam MS. Postmortem study of atherosclerosis in the aorta and coronary arteries in Bangladeshi males [thesis]. Dhaka: University of Dhaka, 1996.

9. Yamamoto. Blood velocity profiles in he human renal artery by doppler ultrasound and their relationship to atherosclerosis. Atherosclerosis 1996; 16: 172-77. 